\title{
Measurement of sedentary behaviour in population health surveys: a review and recommendations
}

\author{
Stephanie A Prince ${ }^{\text {Corresp., }}{ }^{1}$, Allana G LeBlanc ${ }^{1}$, Rachel C Colley ${ }^{2}$, Travis J Saunders ${ }^{3}$ \\ 1 Division of Prevention and Rehabilitation, University of Ottawa Heart Institute, Ottawa, Ontario, Canada \\ 2 Health Analysis Division, Statistics Canada, Ottawa, Ontario, Canada \\ 3 Department of Applied Human Sciences, University of Prince Edward Island, Charlottetown, Prince Edward Island, Canada \\ Corresponding Author: Stephanie A Prince \\ Email address: sprin063@uottawa.ca
}

Background: The purpose of this review was to determine the most valid and reliable questions for targeting key modes of sedentary behaviour (SB) in a broad range of national and international health surveillance surveys. This was done by reviewing the SB modules currently used in population health surveys, as well as examining SB questionnaires that have performed well in psychometric testing. Methods: Health surveillance surveys were identified via scoping review and contact with experts in the field. Previous systematic reviews provided psychometric information on pediatric questionnaires. A comprehensive search of four bibliographic databases was used to identify studies reporting psychometric information for adult questionnaires. Only surveys/studies published/used in English or French were included. Results: The review identified a total of 16 pediatric and 18 adult national/international surveys assessing SB, few of which have undergone psychometric testing. Fourteen pediatric and 35 adult questionnaires with psychometric information were included. While reliability was generally good to excellent for questions targeting key modes of SB, validity was poor to moderate, and reported much less frequently. The most valid and reliable questions targeting specific modes of SB were combined to create a single questionnaire targeting key modes of SB. Discussion: Our results highlight the importance of including SB questions in survey modules that are adaptable, able to assess various modes of SB, and that exhibit adequate reliability and validity. Future research could investigate the psychometric properties of the module we have proposed in this paper, as well as other questionnaires currently used in national and international population health surveys. 
1 Title: Measurement of sedentary behaviour in population health surveys: a review and

2 recommendations

3 Running title: Sedentary behaviour questionnaires

4 Authors: Stephanie A. Prince ${ }^{1 *}$, Allana G. LeBlanc ${ }^{1}$, Rachel C. Colley ${ }^{2}$, Travis J. Saunders ${ }^{3}$

$5{ }^{1}$ Division of Prevention and Rehabilitation, University of Ottawa Heart Institute, Ottawa, Ontario,

6 Canada

$7 \quad{ }^{2}$ Health Analysis Division, Statistics Canada, Ottawa, Ontario, Canada

$8{ }^{3}$ Department of Applied Human Sciences, University of Prince Edward Island, Charlottetown,

9 Prince Edward Island, Canada

10 *Address of corresponding author:

11 Division of Prevention and Rehabilitation, University of Ottawa Heart Institute, 40 Ruskin Street,

12 Ottawa, Ontario, K1Y 4W7, Canada. Email: sprinceware@ottawaheart.ca; sprin063@uottawa.ca

13 Phone: 613-696-7000. 
15 Background: The purpose of this review was to determine the most valid and reliable questions

16 for targeting key modes of sedentary behaviour (SB) in a broad range of national and

17 international health surveillance surveys. This was done by reviewing the SB modules currently

18 used in population health surveys, as well as examining SB questionnaires that have performed

19 well in psychometric testing.

20 Methods: Health surveillance surveys were identified via scoping review and contact with

21 experts in the field. Previous systematic reviews provided psychometric information on pediatric

22 questionnaires. A comprehensive search of four bibliographic databases was used to identify

23 studies reporting psychometric information for adult questionnaires. Only surveys/studies

24 published/used in English or French were included.

25 Results: The review identified a total of 16 pediatric and 18 adult national/international surveys

26 assessing SB, few of which have undergone psychometric testing. Fourteen pediatric and 35 adult

27 questionnaires with psychometric information were included. While reliability was generally

28 good to excellent for questions targeting key modes of SB, validity was poor to moderate, and

29 reported much less frequently. The most valid and reliable questions targeting specific modes of

30 SB were combined to create a single questionnaire targeting key modes of SB.

31 Discussion: Our results highlight the importance of including SB questions in survey modules

32 that are adaptable, able to assess various modes of $\mathrm{SB}$, and that exhibit adequate reliability and

33 validity. Future research could investigate the psychometric properties of the module we have

34 proposed in this paper, as well as other questionnaires currently used in national and international

35 population health surveys.

\section{INTRODUCTION}


37 Sedentary behaviour (SB; sitting, and activities that require very low energy expenditure and

38 done while sitting or reclining [1]) is a unique risk factor for several chronic diseases and

39 mortality [2-6]. Recognition and interest in this risk factor has prompted the inclusion of

40 measures of SB in population health surveillance surveys around the world [6-10]. While self-

41 report tools provide information about mode and domains of SB, little is known about their

42 validity (the degree to which the questionnaire measures what it claims to measure) and

43 reliability (the degree to which a questionnaire can produce consistent and reproducible results)

$44[5,11]$. Habitual patterns of SB can be measured objectively using accelerometers and

45 inclinometers, but these methods are often too time or resource intensive for inclusion in

46 population level health surveys and studies. Further, these objective methodologies are unable to

47 distinguish between different domains (e.g. occupational/school, transportation, leisure,

48 domestic) and modes (e.g., TV, computer use, reading, car driving) of SB. This is an important

49 issue, given that some modes of SB appear to be more consistently associated with indicators of

50 poor health than others. For example, the relationship between total SB and health outcomes is

51 often weaker than for some specific modes of SB, especially TV viewing and total screen time [5,

52 12, 13]. A smaller body of research suggests that sedentary transportation may also show

53 deleterious associations with health [14], whereas reading has been shown to be benign or even

54 beneficial $[5,15]$. It is important to note, however, that further research is still needed to identify

55 whether these associations are independent of other confounding factors such as food

56 consumption and socio-economic status.

57 While two recent systematic reviews have examined the reliability and validity of SB

58 questionnaires in pediatric populations $[16,17]$, no reviews have compared the psychometric

59 properties of SB questionnaires in adults, and none have examined those used in population level

60 surveys. Therefore, the objectives of the present review were to: 1) summarize the available self- 
61 report tools for assessing the most common modes of SB including TV viewing, computer use,

62 total screen time, reading, sedentary transportation, and total SB in national and international

63 population surveillance surveys; and, 2) to identify the most valid and reliable

64 questions/questionnaires for assessing total and individual modalities of SB. We aim to provide

65 readers with practical and evidence-informed information to support the development of future

66 population health surveys.

\section{METHODS}

\section{Inclusion and Exclusion Criteria}

69 The present review focuses on questionnaires used in national and international surveys, as well

70 as those that have undergone formal testing for validity and/or reliability. Activity diaries and

71 ecological momentary assessment tools were excluded from the review due to their low level of

72 practicality within the context of population health surveys. Surveys and any associated

73 validity/reliability testing had to be in English or French to be included in this review.

\section{National/International Survey Questions}

75 To be included in the present review, surveys had to assess SB (e.g. sitting/reclining and an

76 energy expenditure $\leq 1.5$ metabolic equivalents [1]), as opposed to the lack of physical activity

77 (often referred to as physical inactivity). Questionnaires were excluded if we were unable to

78 obtain complete wording for SB items within the questionnaire. Questionnaires used to assess SB

79 in multiple regions in an individual country were considered national in scope, while those that

80 assessed SB in multiple countries were considered international. Surveys that examined only a

81 specific location or region within a country were excluded, as were surveys that examined special

82 populations (e.g. those with a specific disease or condition). 
83 Studies Evaluating Questionnaire Reliability and Validity

84 To be included in the present review, individual studies required at least 30 participants per

85 analysis to ensure adequate power $(80 \%, \alpha=0.05)$ to identify a moderate correlation $(\mathrm{r}=0.50)$

86 between self-report and objective measures.

\section{Search Strategy}

\section{National/International Survey Questionnaires}

89 National and international survey questionnaires were identified via the reference databases of

90 the authors and through a scoping review using the Google search engine. An email was also sent

91 to members of the Sedentary Behaviour Research Network (SBRN; a research network of over

921,100 scientists with an interest in SB, www.sedentarybehaviour.org) asking for help in the

93 identification of additional national and international surveys with questions or components

94 measuring SBs.

\section{Studies Evaluating Questionnaire Reliability and Validity}

96 Similar to the search for national and international SB questionnaires, studies examining the

97 validity and reliability of SB questionnaires were first identified via personal reference databases,

98 then through email correspondence with SBRN members. During this process, we identified two

99 recent systematic reviews that had summarized the reliability and validity of SB questionnaires in

100 children and youth $[16,17]$. These reviews provided a high quality summary of the current

101 evidence and were used to inform our discussion on reliability and validity of SB questionnaires

102 among the pediatric population.

103 We were unable to identify any similar review of SB questionnaires among adults. As a result, we 104 performed a search of the literature to identify relevant studies in adults (aged $>18$ years). A 
105 search strategy (Supplemental Table 1) was carried out in four electronic databases including:

106 Ovid MEDLINE(R) In-Process (1946 - November Week 1 2016); Ovid PsycINFO (1806 to

107 November Week 1 2016); EBSCOhost SPORTDiscus (1830 to November 2016); and EBM

108 Reviews - Cochrane Database of Systematic Reviews 2005 to November 1, 2016). The search

109 sought to identify studies that reported on the validity and/or reliability of a self-report tool (i.e., 110 questionnaire, survey) that measures SB.

111 Assessment of Reliability and Validity

112 In the context of this review, a SB measurement tool with high reliability consistently provides

113 similar estimates of SB across multiple trials. Test-retest reliability is often assessed in SB

114 research using an intraclass correlation coefficient (ICC). Cronbach's $\alpha$ is used to test for internal

115 consistency of a tool. Both measures produce values ranging from 0 to 1 ; where 1 represents

116 perfect reliability and consistent results and 0 represents no reliability or inconsistent results. It is

117 therefore ideal to have an ICC and Cronbach $\alpha$ as close to 1 as possible, with anything over 0.75

118 considered excellent. In the present review, an ICC between 0.60 and 0.74 was considered good,

119 an ICC between 0.40 and 0.59 was considered fair, and an ICC $<0.40$ was considered poor [18].

120 Identifying whether a self-report tool is able to accurately quantify SB is referred to as criterion

121 validity. Validity of a self-report SB measure is often assessed against objective measures (e.g.,

122 activPAL $^{\mathrm{TM}}$, accelerometer, direct observation). The majority of validation studies report a level

123 of correlation between two measures (e.g., questionnaire and accelerometer-measured sedentary

124 time) and similar to the ICC, a correlation coefficient closer to 1 was used to indicate a stronger

125 relationship. We also examined, when available, mean differences and levels of agreement

126 between the self-report and objective measures. 
127 Validity and reliability statistics were extracted in the format provided by the individual studies.

128 Inclinometry was considered the gold standard for total SB and sitting time (e.g. activPAL),

129 which has been shown to have the highest sensitivity for distinguishing between sitting and

130 standing $[19,20]$. Accelerometry was also considered as a criterion measure to assess validity.

131 Although accelerometry provides an objective measurement of time spent sedentary, it is not as

132 sensitive as inclinometry for measuring SB because of its inability to distinguish between

133 stationary standing and sitting and may therefore misclassify some standing time as SB [19, 20].

134 Inclinometry and accelerometry were not considered appropriate criterion standards for specific

135 SB modalities (e.g., TV time, reading). Rather, direct observation or detailed diaries/logs were

136 considered as useful measures for looking at the validity of questionnaires which measured

137 specific modalities of SB.

138 RESULTS

139 Sedentary Behaviour Questions used in National/International Surveys and Studies

140 The review identified a total of 16 pediatric and 18 adult national/international surveys and large

141 national epidemiological studies assessing at least one modality of SB (Supplemental table 1).

142 Pediatric surveys meeting inclusion criteria were used in 38 countries, while we identified adult

143 surveys used in 22 countries. Surveys included as few as one question (e.g., Global Physical

144 Activity Questionnaire [GPAQ], European Prospective Investigation into Cancer and Nutrition-

145 Potsdam Study [EPIC]), and as many as 12 questions (Children's Leisure Activities Survey

146 [CLASS]) related to SB. Although all included questionnaires employed English or French

147 versions, many had also been translated into other languages for specific populations. There was

148 a considerable lack of published literature reporting on psychometric testing for the majority

149 (pediatric $=63 \%$, adult $=56 \%$ ) of the questionnaires used in national and international surveys

150 for all age groups. SB modalities varied across questionnaires, with TV viewing time being the 
151 most frequently assessed (pediatric $=100 \%$, adults $=72 \%$ ). Computer and $/$ or video game time

152 were also frequently assessed, especially among pediatric populations (pediatric $=88 \%$, adults $=$

$15339 \%$ ). Fewer surveys included questions related to reading (pediatric $=44 \%$, adults $=50 \%$ ) or

154 sedentary transport (pediatric $=13 \%$, adult $=33 \%$ ). The wording of questions varied across

155 surveys, although often in relatively trivial ways (e.g., reporting in hours versus minutes). Many

156 (pediatric $=38 \%$, adults $=44 \%$ ), but not all, of the surveys referred to a specific time period for

157 recall (e.g., the past week, four weeks, three months, or year), and reminded participants to focus

158 on a "typical" or "usual" day or week in that time period. Some surveys focused on hours per day

159 of each SB mode, whereas others focused on hours per week. Some surveys asked about an

160 average of the days of the week, while others had separate questions for school/work/week days

161 and weekends. Several (pediatric $=63 \%$, adults $=28 \%$ ) of the surveys separated their questions

162 for each modality of SB (e.g., Canadian Health Measures Survey [CHMS], ISCOLE, HBSC, etc).

163 Some surveys employed the use of a grid or list of SB modalities (e.g. COMPASS) and required

164 participants to enter daily time for each SB.

\section{Reliability and Validity of Individual Questionnaires}

166 The reliability and validity of individual questionnaires has been summarized in Supplemental

167 table 3. Items/questions from these questionnaires can be found on the SBRN website

168 (http://www.sedentarybehaviour.org/files/?get=SB-questionnaires-spreadsheet-October-24-

169 2017.xlsx $)$. We identified 14 questionnaires from previous systematic reviews [16, 17] which

170 have undergone psychometric testing in a pediatric population. Through our search strategy

171 (Figure 1), we identified 35 adult questionnaires with published psychometric properties

172 (multiple papers reported on the psychometric testing of the same questionnaire) that examined

173 the validity and/or reliability of adult SB questionnaires. Included questionnaires contained as

174 few as one question (e.g., GPAQ, Yale Physical Activity Survey for Older Adults [YPAS], Past 
175 Year Physical Activity Questionnaire, Past-Week Modifiable Activity Questionnaire [PWMAP],

176 Modified MONICA Optional Study on Physical Activity Questionnaire [MOSPA-Q]) [21-26],

177 and as many as 23 (Adolescent Sedentary Activities Questionnaire [ASAQ] [27]) items related to

178 SB. Although we identified studies examining the reliability of questions related to key SB

179 modalities, only the measurement of total SB and total sitting time employed appropriate

180 criterion standards for validity.

181 TV viewing

182 Among preschool-aged children and youth, both the Preschool-aged Physical Activity

183 Questionnaire (Pre-PAQ) (ICC $=0.70-0.88,95 \%$ CI: not reported [NR]) [28] and the proxy-

184 report questionnaire used in the Health, Eating and Play Study (HEAPS) (ICC = 0.78, 95\% CI:

185 0.69-0.84) [29], had excellent levels of reliability. Testing of the COMPASS questionnaire in

186 children in grades 9-12 yielded a fair ICC of 0.56 (95\% CI: NR), and a Cronbach's $\alpha$ of 0.74 [30],

187 which was the highest identified in this age group. Among adults, the Sedentary Behavior

188 Questionnaire (SBQ) demonstrated excellent reliability for weekday ( $\mathrm{ICC}=0.86,95 \%$ CI: 0.76,

189 0.92) and for weekend (ICC $=0.83,95 \%$ CI: 0.72, 0.90) TV viewing [31], while the Past Week

190 Modifiable Activity Questionnaire (PWMAQ; ICC = 0.67, 95\% CI: 0.61, 0.71) [24], Salmon SB

191 questionnaire (ICC $=0.82,95 \%$ CI: 0.75, 0.87) [32]/Measure of Older Adults Sedentary Time

192 (MOST; ICC $=0.76,95 \%$ CI: 0.62, 0.86) [32, 33], Sedentary, Transportation and Activity

193 Questionnaire (STAQ; ICC $=0.79,95 \%$ CI: 0.61, 0.89) [34], and the SIT-Q (ICC $=0.84,95 \%$ CI:

$1940.75,0.90)[35]$ also had very reliable questions for TV time. These questionnaires varied in both

195 the wording of the questions and in response categories, suggesting that a variety of approaches

196 provide reliable results for TV viewing. Few studies have compared appropriate objective

197 measures of TV-specific SB to self-reported TV time. Among children, the Youth Risk Behaviour

198 Survey TV time questions were validated against a 7-day TV log and exhibited a moderate 
199 correlation $(\mathrm{r}=0.46)$ [36]. Among adults, the Salmon SB questionnaire was poorly correlated $(\mathrm{r}=$ $2000.3, \mathrm{p}<0.01)$ with 3-day logs for measures of self-reported TV time [32].

\section{Computer, Tablet and Video Game Use}

202 Compared to TV viewing, relatively few (pediatric $=19 \%$, adult $=11 \%$ ) questionnaires have 203 undergone psychometric testing for items related to computer use. Among pre-school aged

204 children and youth, the Pre-PAQ proxy-report questionnaire demonstrated high levels of test205 retest reliability for computer and video game playing (ICC $=0.82-0.85,95 \%$ CI: NR) [28]. The

206 COMPASS questionnaire had slightly lower, but still good levels of reliability on questions 207 related to computer and video game use (ICC $=0.65,95 \% \mathrm{CI}: \mathrm{NR}$, Cronbach's $\alpha=0.79)$ and 208 surfing the internet ( ICC $=0.71,95 \% \mathrm{CI}$ : NR, Cronbach's $\alpha=0.84$ ) among high school students

209 [30]. Among adults, the Gennuso et al. SB questionnaire (ICC $=0.93, \mathrm{p}<.001)$ [37] and the

210 Measure of Older Adults' Sedentary time (MOST) $(\mathrm{ICC}=0.79,95 \% \mathrm{CI}: 0.65,0.86)[33]$ had

211 very high reliability for the question targeting computer and internet use. Similarly, the SBQ [31] 212 has shown high reliability (weekday: $\mathrm{ICC}=0.83 ; 95 \% \mathrm{CI}: 0.72,0.90$, weekend: $\mathrm{ICC}=0.80 ; 95 \%$

213 CI: $0.67,0.88$ ) for a question focusing on computer and video game use. The Marshall Sitting

214 Time Questionnaire asks a single question targeting home-based computer use and has

215 demonstrated good reliability (women: weekday ICC $=0.63,95 \%$ CI: 0.52, 0.71; weekend ICC $=$ $2160.72,95 \%$ CI: 0.64, 0.79, men: weekday ICC $=0.62,95 \%$ CI: 0.48, 0.73; weekend ICC $=0.59$, 217 95\% CI: 0.44, 0.71) [38]. Finally, the French version of the STAQ asks a question on time spent 218 in all forms of computer, tablet and video game use, and has shown to have good reliability (ICC $219=0.64,95 \%$ CI: $0.38,0.80)[34]$.

220 Among adults, the Salmon SB questionnaire used three-day logs to validate self-reported 221 computer use $(r=0.60)$ [32]. Only one study was found to compare a specific modality of SB 
222 with an appropriate objective measure. The Workplace Computer Use Questionnaire compared

223 self-reported occupational computer use to direct observation and found they were moderately

224 correlated $(\mathrm{r}=0.41, \mathrm{p}=0.001)$, reliability was not assessed [39].

\section{Total Screen Time}

226 The ASAQ reported excellent reliability (grade 6 girls: $\mathrm{ICC}=0.76,95 \% \mathrm{CI}: 0.57,0.87$ to grade 8

227 boys: $\mathrm{ICC}=0.90,95 \% \mathrm{CI}: 0.82,0.95)$ for the measure of total screen time, which was calculated 228 as the sum of all time watching TV, videos, DVDs, and using a computer for fun or homework.

229 [27] The STAQ (ICC = 0.70, 95\% CI: 0.48, 0.84) [34] and Domain-Specific Last 7-d Sedentary

230 Time Questionnaire (SIT-Q-7d) (average day ICC $=0.61,95 \%$ CI: 0.53, 0.67) [40] also

231 demonstrated good reliability for total screen time calculated as the sum of individual screen-

232 based behaviours in adults.

233 Reading

234 We were unable to identify any studies examining the reliability or validity of reading questions

235 in children and youth. Although the ASAQ includes a question on reading, to our knowledge its

236 reliability and validity have not been reported. In contrast, several questionnaires have undergone

237 psychometric testing for items related to reading in adults. The Salmon SB questionnaire had the

238 best level of reliability for reading with an ICC of 0.78 (95\% CI: $0.69,0.84)[32,33]$. The MOST

239 (adapted from Salmon's questionnaire; ICC $=0.74,95 \%$ CI: 0.51, 0.86) [33], SBQ (weekday:

$240 \mathrm{ICC}=0.64,95 \%$ CI: 0.44, 0.78, weekend: $\mathrm{ICC}=0.48,95 \%$ CI: 0.24, 0.67) [31] and Sit-Q-7D

241 (ICC $=0.59,95 \%$ CI: 0.51, 0.66) [40] had slightly lower reliability, although it should be pointed

242 out that there were only minor differences in wording across the three questionnaires, and all

243 ICCs fell in the "fair to excellent" range. Reading time from the Salmon SB questionnaire was 
244 validated against a three-day log and a low correlation between the two measures $(\mathrm{r}=0.20)$ was

245 reported [32].

\section{Stationary Transportation}

247 The reliability of the Pre-PAQ proxy-report questionnaire ranged from poor to good $(\mathrm{ICC}=0.31$ -

$2480.63,95 \% \mathrm{CI}: \mathrm{NR}$ ) for a question focusing on the amount of car time over the past week in pre-

249 school aged children [28]. The ASAQ question focusing on time spent in a car, bus or train has

250 good reliability (average ICC $=0.61$ ) in boys and girls in grades 6,8 and 10 , but performed

251 significantly better in girls than boys (e.g., grade 10 girls ICC $=0.93,95 \%$ CI: 0.85, 0.97 vs.

252 grade 10 boys: ICC $=0.25,95 \%$ CI: $-0.31,0.57$ ) [27]. Among adults, the International Physical

253 Activity Questionnaire (IPAQ; $r=0.81-0.91$ ) [41] and the Salmon SB questionnaire (ICC $=0.85$,

$25495 \%$ CI: 0.79, 0.89) [32] had excellent reliability for weekly passive transport. The SBQ also has

255 excellent reliability for both weekday $(\mathrm{ICC}=0.76,95 \% \mathrm{CI}: 0.61,0.86)$ and weekend days $(\mathrm{ICC}=$

$2560.72,95 \%$ CI: 0.56, 0.83) [31]. The SIT-Q had good reliability for both weekday $(\mathrm{ICC}=0.65$,

257 95\% CI: 0.48, 0.77) and weekend days (ICC = 0.51 (95\% CI: 0.30, 0.67) [35].

258 Total Sedentary Behaviour

259 Total SB was the only outcome for which we could find comparisons to appropriate objective 260 standards in any age group. Among children and youth, estimated after-school SB (a composite 261 score of TV, computer and cell-phone time) from the Youth Activity Profile (YAP) was highly 262 correlated $(\mathrm{r}=0.75, P<0.001)$ with total sedentary time from the Sensewear armband [42]. The

263 Activity Questionnaire for Adults and Adolescents (AQuAA; r = 0.23, $P>0.05$ ),[43] COMPASS

$264(\mathrm{r}=0.20 ; \mathrm{p}<0.05)[30]$ and Physical Activity and Sedentary Behavior Assessment Questionnaire

265 (PASBAQ) ( $\mathrm{r}=0.20-0.27)$ [44] reported low correlations between self-reported total SB

266 (calculated as the sum of all SB modalities) and hip-worn accelerometers in pediatric 
267 populations. Importantly, the COMPASS questionnaire also presented with high levels of test-

268 retest reliability $(\mathrm{ICC}=0.79,95 \% \mathrm{CI}$ : NR) [30]. We did not identify any studies examining the

269 validity of questions of total sitting time in children and youth, though most of the items for total

270 SB are likely to be accomplished while sitting.

271 Among adults, validation studies have looked at single item estimates of sitting time, or have

272 generated a composite score from a number of items to estimate total SB. The Past-day Adults'

273 Sedentary Time (PAST) and Past-Adults' Sedentary Time - University (PAST-U) questionnaires

274 had the highest measures of validity (PAST: $r=0.57,95 \%$ CI: $0.39,0.71$, PAST-U: $r=0.63,95 \%$

275 CI: $0.44,0.76)$ between a total of sum of SBs and sedentary time from the activPAL $[45,46]$. The

276 questionnaire from the AusDiab3 Study ( $r=0.46,95 \%$ CI: 0.40, 0.52) [47] and the Madras

277 Diabetes Research Foundation Physical Activity Questionnaire (MPAQ; r = 0.48, 95\% CI: 0.32,

278 062) [48] also had moderate agreement with objective measures. In addition, the MPAQ also had

279 excellent reliability for all sitting time (ICC $=0.81,95 \%$ CI: 0.78, 0.84) [48]. The Salmon SB

280 questionnaire had excellent reliability for total SB (ICC $=0.79,95 \%$ CI: 0.71, 0.85) [32]. Even

281 though the IPAQ is one of the most frequently used tools for self-reported SB, it relates poorly to

282 objective measures. The validity of the IPAQ has been examined in multiple studies using

283 accelerometers and inclinometers, with correlations generally ranging between 0.22 and 0.50

284 (depending on study sample), but with correlations for test-retest reliability generally above 0.70 $285[41,49-51]$.

\section{DISCUSSION}

287 The purpose of the present review was to summarize the questions used to assess SB in national

288 and international population surveillance surveys, and to identify the most valid and reliable

289 questions for measuring both total SB and specific sub-domains and modes of SB. Although we 
290 identified a large number of national/international surveys, as well as a relatively large number of

291 questionnaires with published results from psychometric testing, we found there was relatively

292 little overlap between the two groups. Questions used in large population health surveys have

293 typically not undergone appropriate evaluation with respect to validity or reliability, whereas

294 questionnaires that have undergone this psychometric testing have typically not been used in

295 larger national/international surveys.

296 Of the various modalities of SB, available evidence suggests that in general, self-reported total

297 SB, TV viewing, computer use, and total screen time are negatively associated with physical and 298 psychosocial health indicators in both children and adults $[5,12,52]$. Although it has been the

299 focus of relatively few studies, the opposite relationship is observed for reading, which is

300 associated with higher levels of academic achievement in children, and increased longevity in 301 adults $[5,15]$. It is unclear whether these relationships are due to physiological mechanisms, or

302 due to confounding via other variables (e.g., socio-economic status), though at present there is

303 little evidence to suggest that reading per se has a negative impact on health. Limited evidence

304 suggests that transportation-related and occupational sedentary time may also be associated with

305 poor health outcomes $[14,53]$. However, to our knowledge there is no evidence to suggest that

306 the health impact of occupational sedentary time is different from that of total sedentary time, or

307 that the impact of occupational computer use is different than that of non-occupational computer

308 use. A sum of all modalities of SB is important for providing prevalence estimates of sedentary

309 time; however, specific modalities of SB associate differently with health and are useful for

310 surveillance. Given their consistent and deleterious associations with health indicators, and high

311 prevalence of daily use, we suggest that TV time, computer time and total screen time are the

312 self-report modalities of SB of greatest importance to include in population health surveys. We 
313 also suggest that if feasible, time spent in sedentary transport and reading are worth measuring

314 and may provide insightful information.

315 As noted earlier, objective measurement tools (e.g., inclinometers and accelerometers) can only

316 be used to test the validity of questions, or series of questions, aimed at estimating total sedentary

317 time. The studies included in this review show poor validity in total SB when various

318 questionnaires are assessed against objective measures. Similarly, Hidding et al. reported an

319 absence of SB questionnaires that are both reliable and valid for use among children and youth

320 [16]. Important to consider is that although accelerometers and inclinometers can help to validate

321 sitting time questionnaires, they are unable to tell if a specific question accurately assesses

322 specific modalities of SB (e.g., TV viewing, computer use, etc.). The questionnaires that

323 performed best when compared to objective measures, specifically the PAST [45] and PAST-U

324 [46], asked participants to record their time spent in nine different modes of SB, the sum of which

325 provided a measure of total SB time. It is recognized, however, that a nine-item questionnaire is

326 likely prohibitively long for inclusion in population surveillance surveys that are designed to

327 obtain broad-level indicators of health across a large number of areas. The review was unable to

328 locate any studies that examined the validity criterion of questions measuring screen time,

329 reading or sedentary transportation. This is not surprising given the inability of objective

330 measurement devices to delineate one type of SB from another. Thus, it is unclear whether

331 answers to these questionnaires represent an accurate depiction of an individual's time spent in

332 highly prevalent modalities of SB. It is also important, to identify the main limitation of this

333 paper; the absence of a systematic and comprehensive search strategy. It is therefore, likely that

334 there are questionnaires/surveys that have not been captured in the review. 
335 Importantly, while the validity of most self- and proxy-report SB health surveillance surveys are

336 unknown, they still appear to provide useful measures of risk associated with health behaviours.

337 In fact, self-reported SBs tend to be more strongly associated with health outcomes than objective

338 measures, especially among children and youth $[5,54,55]$. This suggests that it may be the

339 behaviours done while sedentary (e.g., watching TV vs. reading) that are more important than

340 total SB [55]. In addition, recall of specific SBs like screen time is likely easier than recalling all

341 instances of sitting time throughout the day. Further, the available evidence does not suggest that

342 SB questionnaires are invalid; rather that the validity of most questionnaires, especially those

343 used in national/international surveillance surveys, have not been assessed against appropriate

344 criterion measures. As noted elsewhere, objective and subjective measures of SB provide

345 different, but complementary, information [56]. Therefore, it is recommended that population

346 health surveys consider employing both types of measures where feasible (i.e., both an

347 inclinometer and a questionnaire).

348 In contrast to validity, we identified several questionnaires with acceptable reliability for the

349 assessment of various SB domains in both adults and children. Reliability is a key factor for

350 population surveillance surveys where the assessment of SBs over time are important to monitor

351 the prevalence of this risk factor, as well as to evaluate changes resulting from population-level

352 interventions [57]. While it would be ideal to have access to questionnaires that are known to be

353 both valid and reliable, it is still useful and important to know that reliable options do exist for

354 the measurement of important SB modalities. It is important to consider that a tool that has shown

355 to be reliable at one time point, may lose its relevance and require updating with the emergence

356 of new modes of SB as a result from changes in technology and its use. We recognize that

357 reliability results did vary substantially between measures. Some of this variation may be a result

358 of the population in which reliability of the questionnaire was assessed (e.g. general vs. special 
359 population) and the context (e.g., study looking only at reliability and validity of questionnaire

360 vs. assessing reliability and validity within a pre-existing study).

361

362

363

364 365

371 methodology.

372 It is important that surveillance surveys assess the types of SBs that reflect those which are most

373 used in the population and recognize that these may change over time. For example, many

374 individuals now watch television programming over internet streaming services such as Netflix or YouTube in addition to (or instead of) traditional cable or satellite TV. One option to ensure new forms of SB emerge.

379 We also recommend that population surveillance surveys ensure that the questions used to 380

\section{Additional factors for consideration}

In addition to validity and reliability, there are several other factors of relevance when attempting to determine the ideal means for assessing SB in population surveillance surveys. For example, it has been noted that individuals are increasingly engaged in "multi-tasking", whereby they are participating in multiple forms of SB simultaneously [58]. For example, individuals may be reading or playing a video game on a tablet while also watching TV. If the total time spent doing each of these activities is simply summed together, this can result in inflated estimates for total screen time or total SB [59]. Some of the questionnaires identified in this review (e.g. the MOST questionnaire) address this issue using a pre-amble to ask respondents to only identify the "main" form of SB during a given time period. We recommend that future surveys incorporate this that the most current SB modes are assessed is through the consistent use of relatively generic questions for each SB modality, with detailed examples provided beneath that can be updated as 
381 health guidelines. For example, Canadian guidelines recommend that school-aged children and

382 youth accrue no more than two hours per day of recreational screen time [60]. It is therefore

383 important that population health surveys provide information in a format which can be used to

384 assess whether or not an individual is meeting such guidelines. In particular, allowing

385 respondents to enter their response as a specific continuous number (e.g. hours and minutes per

386 day or week), or providing a large range of individual options (e.g., 0, 30 minutes, 1 hour, 2

387 hour... 6+ hours) allows this to be easily calculated. These approaches have been used by several

388 questionnaires with high levels of reliability in both children and adults (e.g., COMPASS, SBQ).

389 Importantly however, scaled response categories preclude the ability to determine specific

390 durations of SB for those in the highest category (e.g. if a person answers "6+ hours" you will not

391 know if they engaged in 6 hours versus 12 hours of screen time). This can complicate data

392 analysis, as well as in the interpretation of "average" time spent in a SB across a population.

393 Finally, with respect to population surveillance surveys, it is important that they remain

394 consistent, whenever possible, to provide information on secular trends in SBs over time. The

395 questions used to assess SB vary widely across national and international surveys, often change

396 over time, and do not always target the same domains of SB (e.g., screen time, leisure,

397 occupational, transport, etc.). These issues preclude meaningful comparisons over time, or across

398 countries and regions, and diminish the usefulness of the information provided by these

399 surveys/questionnaires for researchers, health behaviour interventionists and policy makers.

400 Thus, it is recommended that population health surveys should use consistent questions from

401 year-to-year whenever possible.

402 Suggested SB Module 
403 Table 1 provides a suggested SB module that we developed using modified individual questions

404 from other questionnaires with acceptable reliability. Examples have been provided in brackets

405 for some questions; these can be updated over time as new popular modes of SB emerge (e.g. a

406 new Smartphone or internet streaming service). We have proposed individual questions for time

407 spent using screens, watching TV, using computers (including tablets, smart phones, and video

408 games), reading, in sedentary transportation, and total sitting time. To address SB guidelines for

409 children and youth, the caveat "during your free time" can be added for questions related to

410 screen time for children and youth, but not adults [60]. For each question, answers are reported in

411 a continuous fashion using hours and minutes per week. This approach allows the researcher to

412 easily determine whether an individual is meeting or exceeding public health guidelines, which

413 can be difficult (and sometimes impossible) when using categorical variables. As noted above,

414 this is the approach used by several questionnaires that performed well on test-retest reliability.

415 The preambles from the MOST and SBQ questionnaires have also been adapted in an attempt to

416 minimize the impact of multitasking.

417 Reading was included given that it is the only form of SB consistently associated with positive

418 health indicators [15]. At present it is unclear whether the health impacts of reading on a screen-

419 based device differ from those of reading a physical book. Studies that have shown associations

420 between reading and academic achievement or longevity tend to simply ask how much time

421 people spend reading books or magazines, without specifying the device used [15, 61]. As books

422 and magazines are likely to be increasingly read on screen-based devices, more research will be

423 needed to determine if this has any impact on the relationship between reading and health, which

424 may also differ based on the specific screen-based device being use (e.g. lit screens may have a

425 more detrimental impact on sleep than non-lit screens [62]). For now, it is suggested to include 
426 wording similar to that used in the 2015 CHMS [63], which includes reading done using both

427 physical books and electronic devices.

428 The questions are listed in order of their importance, based on their associations with health

429 outcomes. The options also recognize the need for population surveys that include SB measures

430 may have limited space for questions regarding a single health behaviour. Therefore, if there is

431 room for only one question, then question 1 (Screen time) should be used. If there is room for

432 two questions, then questions 2 (TV time) and 3 (Computer time) should be used; this allows the

433 researcher to also calculate total screen time (i.e. will provide a response for question 1). If the

434 survey allows for more items, we suggest adding questions 4 to 6 sequentially.

435 To date, many SB questionnaires have separated weekdays from weekend days. This is especially

436 true in the pediatric population, where the majority of questionnaires separate week (or school)

437 and weekend days. This format is recommended as individuals often have very different and

438 sometimes counter-intuitive schedules on weekdays versus weekend days. In line with this

439 practice, we have suggested that each question be asked twice; once for weekdays, and once for

440 weekend days.

\section{CONCLUSIONS}

442 This review aimed to describe SB modules that have been commonly used in national and

443 international surveys. We also aimed to identify the most reliable and valid tools currently

444 available to assess SB. Unfortunately, we were unable to identify a single tool that met all of our

445 criteria. As such, we have recommended a new module, based on the best available evidence that

446 can be modified to suit the needs of individual surveys. Future research could investigate the 
447 psychometric properties of the proposed module, as well as other questionnaires currently used in 448 national and international population health surveys.

\section{ACKNOWLEDGEMENTS}

450 Travis Saunders is the senior author of the publication.

451 REFERENCES

452 1. Sedentary Behaviour Research Network. Letter to the editor: standardized use of the terms

453 "sedentary" and "sedentary behaviours". Appl Physiol Nutr Metab. 2012;37(3):540-2.

454 doi:10.1139/h2012-024.

455 2. Biswas A, Oh PI, Faulkner GE, Bajaj RR, Silver MA, Mitchell MS et al. Sedentary time and

456 its association with risk for disease incidence, mortality, and hospitalization in adults: a

457 systematic review and meta-analysis. Ann Intern Med. 2015;162(2):123-32. doi:10.7326/m144581651.

459 3. Wilmot EG, Edwardson CL, Achana FA, Davies MJ, Gorely T, Gray LJ et al. Sedentary time 460 in adults and the association with diabetes, cardiovascular disease and death: systematic review 461 and meta-analysis. Diabetologia. 2012;55(11):2895-905. doi:10.1007/s00125-012-2677-z.

462 4. Thorp AA, Owen N, Neuhaus M, Dunstan DW. Sedentary behaviors and subsequent health 463 outcomes in adults a systematic review of longitudinal studies, 1996-2011. Am J Prev Med. 464 2011;41(2):207-15. doi:10.1016/j.amepre.2011.05.004.

465 5. Carson V, Hunter S, Kuzik N, Gray CE, Poitras VJ, Chaput JP et al. Systematic review of 466 sedentary behaviour and health indicators in school-aged children and youth: an update. Appl 467 Physiol Nutr Metab. 2016;41(6 Suppl 3):S240-65. doi:10.1139/apnm-2015-0630. 
468 6. Colley RC, Garriguet D, Janssen I, Craig CL, Clarke J, Tremblay MS. Physical activity of

469 Canadian adults: accelerometer results from the 2007 to 2009 Canadian Health Measures Survey.

470 Health Rep. 2011;22(1):7-14.

471 7. Colley RC, Garriguet D, Janssen I, Craig CL, Clarke J, Tremblay MS. Physical activity of

472 Canadian children and youth: accelerometer results from the 2007 to 2009 Canadian Health

473 Measures Survey. Health Rep. 2011;22(1):15-23.

474 8. Matthews CE, Chen KY, Freedson PS, Buchowski MS, Beech BM, Pate RR et al. Amount of

475 time spent in sedentary behaviors in the United States, 2003-2004. Am J Epidemiol.

476 2008;167(7):875-81. doi:10.1093/aje/kwm390.

477 9. Statistics ABo. National Nutrition and Physical Activity Survey 2011-12. 2011.

478 http://www.ausstats.abs.gov.au/ausstats/subscriber.nsf/0/734DF823586D5AD9CA257B8E0014A

479 387/\$File/national $\% 20$ nutrition $\% 20$ and $\% 20$ physical $\% 20$ activity $\% 20$ survey $\% 202011$ -

$480 \quad 12 \% 20$ questionnaire.pdf. Accessed February 5, 2017.

481 10. Scottish Centre for Social Research. Scottish Health Survey, 2014. In: Service UD, 482 editor.2016.

483 11. Atkin AJ, Gorely T, Clemes SA, Yates T, Edwardson C, Brage S et al. Methods of 484 measurement in epidemiology: sedentary behaviour. Int J Epidemiol. 2012;41(5):1460-71.

485 12. Ford ES, Caspersen CJ. Sedentary behaviour and cardiovascular disease: a review of

486 prospective studies. Int J Epidemiol. 2012;41(5):1338-53. doi:10.1093/ije/dys078.

487 13. Ekelund U, Steene-Johannessen J, Brown WJ, Fagerland MW, Owen N, Powell KE et al.

488 Does physical activity attenuate, or even eliminate, the detrimental association of sitting time

489 with mortality? A harmonised meta-analysis of data from more than 1 million men and women.

490 Lancet. 2016;388(10051):1302-10. doi:10.1016/s0140-6736(16)30370-1. 
491 14. Sugiyama T, Wijndaele K, Koohsari MJ, Tanamas SK, Dunstan DW, Owen N. Adverse

492 associations of car time with markers of cardio-metabolic risk. Prev Med. 2016;83:26-30.

493 doi:10.1016/j.ypmed.2015.11.029.

494 15. Bavishi A, Slade MD, Levy BR. A chapter a day: Association of book reading with longevity.

495 Soc Sci Med. 2016;164:44-8. doi:10.1016/j.socscimed.2016.07.014.

496 16. Hidding LM, Altenburg TM, Mokkink LB, Terwee CB, Chinapaw MJ. Systematic review of

497 childhood sedentary behavior questionnaires: what do we know and what is next? Sports Med.

498 2016. doi:10.1007/s40279-016-0610-1.

499 17. Lubans DR, Hesketh K, Cliff DP, Barnett LM, Salmon J, Dollman J, Morgan PJ, Hills AP,

500 Hardy LL. A systematic review of the validity and reliability of sedentary behaviour measures

501 used with children and adolescents. Obes Rev. 2011;12(10):781-99. doi:10.1111/j.1467-

502 789X.2011.00896.x.

503 18. Cicchetti DV. Guidelines, criteria, and rules of thumb for evaluating normed and standardized

504 assessment instruments in psychology. Psychological assessment. 1994;6(4):284.

505 19. Aminian S, Hinckson EA. Examining the validity of the ActivPAL monitor in measuring

506 posture and ambulatory movement in children. Int J Behav Nutr Phys Act. 2012;9:119.

507 doi:10.1186/1479-5868-9-119.

508 20. Dowd KP, Harrington DM, Donnelly AE. Criterion and concurrent validity of the activPAL

509 professional physical activity monitor in adolescent females. PLoS One. 2012;7(10):e47633.

510 doi:10.1371/journal.pone.0047633.

511 21. Cleland CL, Hunter RF, Kee F, Cupples ME, Sallis JF, Tully MA. Validity of the global

512 physical activity questionnaire (GPAQ) in assessing levels and change in moderate-vigorous

513 physical activity and sedentary behaviour. BMC Public Health. 2014;14:1255. 
514 22. Herrmann SD, Heumann KJ, Der Ananian CA, Ainsworth BE. Validity and reliability of the

515 Global Physical Activity Questionnaire (GPAQ). Measure Phys Educ Exerc Sci. 2013;17(3):221-

516 35. doi:10.1080/1091367X.2013.805139.

517 23. Chau JY, Van Der Ploeg HP, Dunn S, Kurko J, Bauman AE. Validity of the occupational

518 sitting and physical activity questionnaire. Med Sci Sports Exerc. 2012;44(1):118-25.

519 doi:10.1249/MSS.0b013e3182251060.

520 24. Pettee Gabriel K, McClain JJ, Schmid KK, Storti KL, Ainsworth BE. Reliability and

521 convergent validity of the past-week Modifiable Activity Questionnaire. Public Health Nutr.

522 2011;14(3):435-42. doi:10.1017/s1368980010002612.

523 25. Aguilar-Farias N, Brown WJ, Olds TS, Geeske Peeters GM. Validity of self-report methods

524 for measuring sedentary behaviour in older adults. J Sci Med Sport. 2015;18(6):662-6.

525 doi:10.1016/j.jsams.2014.08.004.

526 26. Gennuso KP, Matthews CE, Colbert LH. Reliability and validity of 2 self-report measures to

527 assess sedentary behavior in older adults. J Phys Act Health. 2015;12(5):727-32.

528 doi:10.1123/jpah.2013-0546.

529 27. Hardy LL, Booth ML, Okely AD. The reliability of the Adolescent Sedentary Activity

530 Questionnaire (ASAQ). Prev Med. 2007;45(1):71-4. doi:10.1016/j.ypmed.2007.03.014.

531 28. Dwyer GM, Hardy LL, Peat JK, Baur LA. The validity and reliability of a home environment

532 preschool-age physical activity questionnaire (Pre-PAQ). Int J Behav Nutr Phys Act. 2011;8:86.

533 doi:10.1186/1479-5868-8-86.

534 29. Salmon J, Campbell KJ, Crawford DA. Television viewing habits associated with obesity risk

535 factors: a survey of Melbourne schoolchildren. Med J Aust. 2006;184(2):64-7.

536 30. Leatherdale ST, Laxer RE, Faulkner GE. Reliability and validity of the physical activity and

537 sedentary behaviour measures in the COMPASS study. Waterloo, Ontario: University of

538 Waterloo2014 Contract No.: 1. 
539 31. Rosenberg DE, Norman GJ, Wagner N, Patrick K, Calfas KJ, Sallis JF. Reliability and

540 validity of the Sedentary Behavior Questionnaire (SBQ) for adults. J Phys Act Health.

$541 \quad 2010 ; 7(6): 697-705$.

542 32. Salmon J, Owen N, Crawford D, Bauman A, Sallis JF. Physical activity and sedentary

543 behavior: a population-based study of barriers, enjoyment, and preference. Health Psychol.

$544 \quad 2003 ; 22(2): 178-88$.

545 33. Gardiner PA, Clark BK, Healy GN, Eakin EG, Winkler EA, Owen N. Measuring older adults'

546 sedentary time: reliability, validity, and responsiveness. Med Sci Sports Exerc. 2011;43(11):2127-

547 33. doi:10.1249/MSS.0b013e31821b94f7.

548 34. Mensah K, Maire A, Oppert JM, Dugas J, Charreire H, Weber C, Simon C, Nazare J-A.

549 Assessment of sedentary behaviors and transport-related activities by questionnaire: a validation

550 study. BMC Public Health. 2016;16:753.

551 35. Lynch BM, Fridenrich CM, Khandwala F, Liu A, Nicholas J, Csizmadi I. Development and

552 testing of a past year measure of sedentary behavior: the SIT-Q. BMC Public Health,

$5532014 ; 14: 899$.

554 36. Schmitz KH, Harnack L, Fulton JE, Jacobs DR, Jr., Gao S, Lytle LA et al. Reliability and

555 validity of a brief questionnaire to assess television viewing and computer use by middle school

556 children. J Sch Health. 2004;74(9):370-7.

557 37. Gennuso KP, Thraen-Borowski KM, Gangnon RE, Colbert LH. Patterns of sedentary

558 behavior and physical function in older adults. Aging Clin Exp Res. 2016;28(5):943-50.

559 doi:10.1007/s40520-015-0386-4.

560 38. Marshall AL, Miller YD, Burton NW, Brown WJ. Measuring total and domain-specific

561 sitting: a study of reliability and validity. Med Sci Sports Exerc. 2010;42(6):1094-102.

562 doi:10.1249/MSS.0b013e3181c5ec18. 
563 39. Douwes M, de Kraker H, Blatter BM. Validity of two methods to assess computer use: Self-

564 report by questionnaire and computer use software. Int J Indust Erg. 2007;37(5):425-31.

565 doi:http://dx.doi.org/10.1016/j.ergon.2007.01.002.

566 40. Wijndaele K, I DEB, Godino JG, Lynch BM, Griffin SJ, Westgate K, Brage S. Reliability and

567 validity of a domain-specific last 7-d sedentary time questionnaire. Med Sci Sports Exerc.

568 2014;46(6):1248-60. doi:10.1249/mss.0000000000000214.

569 41. Rosenberg DE, Bull FC, Marshall AL, Sallis JF, Bauman AE. Assessment of sedentary

570 behavior with the International Physical Activity Questionnaire. J Phys Act Health. 2008;5 Suppl

$571 \quad 1: S 30-44$.

572 42. Saint-Maurice PF, Welk GJ. Validity and calibration of the Youth Activity Profile. PLoS One.

573 2015;10(12):e0143949. doi:10.1371/journal.pone.0143949.

574 43. Chinapaw MJ, Slootmaker SM, Schuit AJ, van Zuidam M, van Mechelen W. Reliability and 575 validity of the Activity Questionnaire for Adults and Adolescents (AQuAA). BMC Med Res

576 Methodol. 2009;9:58. doi:10.1186/1471-2288-9-58.

577 44. Scholes S, Coombs N, Pedisic Z, Mindell JS, Bauman A, Rowlands AV, Stamatakis E. Age-

578 and sex-specific criterion validity of the health survey for England Physical Activity and

579 Sedentary Behavior Assessment Questionnaire as compared with accelerometry. Am J Epidemiol.

580 2014;179(12):1493-502. doi:10.1093/aje/kwu087.

581 45. Clark BK, Winkler E, Healy GN, Gardiner PG, Dunstan DW, Owen N, Reeves MM. Adults'

582 past-day recall of sedentary time: reliability, validity, and responsiveness. Med Sci Sports Exerc.

583 2013;45(6):1198-207. doi:10.1249/MSS.0b013e3182837f5

584 46. Clark BK, Pavey TG, Lim RF, Gomersall SR, Brown WJ. Past-day recall of sedentary time:

585 Validity of a self-reported measure of sedentary time in a university population. J Sci Med Sport.

586 2016;19(3):237-41. doi:10.1016/j.jsams.2015.02.001. 
587 47. Clark BK, Lynch BM, Winkler EA, Gardiner PA, Healy GN, Dunstan DW, Owen N. Validity

588 of a multi-context sitting questionnaire across demographically diverse population groups:

589 AusDiab3. Int J Behav Nutr Phys Act. 2015;12:148. doi:10.1186/s12966-015-0309-y.

590 48. Anjana RM, Sudha V, Lakshmipriya N, Subhashini S, Pradeepa R, Geetha L, Bai MR,

591 Gayathri R, Deepa M, Unnikrishnan R, Binu VSN, Kurpad AV, Mohan V. Reliability and validity

592 of a new physical activity questionnaire for India. Int J Behav Nutr Phys Act. 2015;12:40.

593 doi:10.1186/s12966-015-0196-2.

594 49. Craig CL, Marshall AL, Sjostrom M, Bauman AE, Booth ML, Ainsworth BE et al.

595 International physical activity questionnaire: 12-country reliability and validity. Med Sci Sports

596 Exerc. 2003;35(8):1381-95. doi:10.1249/01.mss.0000078924.61453.fb.

597 50. Kolbe-Alexander TL, Lambert EV, Harkins JB, Ekelund U. Comparison of two methods of

598 measuring physical activity in South African older adults. J Aging Phys Act. 2006;14(1):98-114.

599 51. Umstattd Meyer MR, Baller SL, Mitchell SM, Trost SG. Comparison of 3 accelerometer data

600 reduction approaches, step counts, and 2 self-report measures for estimating physical activity in

601 free-living adults. J Phys Act Health. 2013;10(7):1068-74.

602 52. Grontved A, Hu FB. Television viewing and risk of type 2 diabetes, cardiovascular disease,

603 and all-cause mortality: a meta-analysis. JAMA. 2011;305(23):2448-55.

604 doi:10.1001/jama.2011.812.

605 53. van Uffelen JG, Wong J, Chau JY, van der Ploeg HP, Riphagen I, Gilson ND et al.

606 Occupational sitting and health risks: a systematic review. Am J Prev Med. 2010;39(4):379-88.

607 doi:10.1016/j.amepre.2010.05.024.

608 54. Stamatakis E, Davis M, Stathi A, Hamer M. Associations between multiple indicators of

609 objectively-measured and self-reported sedentary behaviour and cardiometabolic risk in older

610 adults. Prev Med. 2012;54(1):82-7. doi:10.1016/j.ypmed.2011.10.009. 
611 55. Cliff DP, Hesketh KD, Vella SA, Hinkley T, Tsiros MD, Ridgers ND et al. Objectively

612 measured sedentary behaviour and health and development in children and adolescents:

613 systematic review and meta-analysis. Obes Rev. 2016;17(4):330-44. doi:10.1111/obr.12371.

614 56. Saunders TJ, Chaput JP, Tremblay MS. Sedentary behaviour as an emerging risk factor for

615 cardiometabolic diseases in children and youth. Can J Diabetes. 2014;38(1):53-61.

616 doi:10.1016/j.jcjd.2013.08.266.

617 57. Herman KM, Saunders TJ. Sedentary behaviours among adults across Canada. Can J Public

618 Health. 2016;107(4-5):e438-e46. doi:10.17269/cjph.107.5587.

619 58. Rideout VJ, Foehr UG, Roberts DF. Generation $\mathrm{M}^{2}$ : Media in the Lives of 8-to 18-Year-Olds.

620 Henry J Kaiser Family Foundation. 2010.

621 59. Saunders TJ, Prince SA, Tremblay MS. Clustering of children's activity behaviour: the use of

622 self-report versus direct measures. Int J Behav Nutr Phys Act. 2011;8:48; author reply 9.

623 doi:10.1186/1479-5868-8-48.

624 60. Tremblay MS, Carson V, Chaput JP, Connor Gorber S, Dinh T, Duggan M et al. Canadian 24-

625 Hour Movement Guidelines for Children and Youth: an integration of physical activity, sedentary

626 behaviour, and sleep. Appl Physiol Nutr Metab. 2016;41(6 Suppl 3):S311-27. doi:10.1139/apnm-

$627 \quad 2016-0151$.

628 61. Romer D, Bagdasarov Z, More E. Older versus newer media and the well-being of United

629 States youth: results from a national longitudinal panel. J Adolesc Health. 2013;52(5):613-9.

630 doi:10.1016/j.jadohealth.2012.11.012.

631 62. Hale L, Guan S. Screen time and sleep among school-aged children and adolescents: a

632 systematic literature review. Sleep Med Rev. 2015;21:50-8. doi:10.1016/j.smrv.2014.07.007.

633 63. Statistics Canada. Canadian Community Health Survey (CCHS) - 2015. 2016.

634 http://www23.statcan.gc.ca/imdb/p3Instr.pl? 
635 Function=assembleInstr\&a=1\&\&lang=en\&Item Id=238890\#qb244767. Accessed February 24, 6362017.

637 64. He M, Harris S, Piche L, Beynon C. Understanding screen-related sedentary behavior and its 638 contributing factors among school-aged children: a social-ecologic exploration. Am J Health 639 Promot. 2009;23(5):299-308. doi:10.4278/ajhp.07070965.

640 65. Treuth MS, Sherwood NE, Butte NF, McClanahan B, Obarzanek E, Zhou A et al. Validity and 641 reliability of activity measures in African-American girls for GEMS. Med Sci Sports Exerc.

642 2003;35(3):532-9. doi:10.1249/01.mss.0000053702.03884.3f.

643 66. Hardy LL, Bass SL, Booth ML. Changes in sedentary behavior among adolescent girls: a 2.5644 year prospective cohort study. J Adolesc Health. 2007;40(2):158-65.

645 doi:10.1016/j.jadohealth.2006.09.009.

646 67. Bonn SE, Surkan PJ, Lagerros YT, Balter K. Feasibility of a novel web-based physical 647 activity questionnaire for young children. Pediatr Rep. 2012;4(4):e37. doi:10.4081/pr.2012.e37.

648 68. Janz KF, Broffitt B, Levy SM. Validation evidence for the Netherlands physical activity 649 questionnaire for young children: the Iowa bone development study. Res Q Exerc Sport. 650 2005;76(3):363-9. doi:10.1080/02701367.2005.10599308.

651 69. Brown TD, Holland BV. Test-retest reliability of the self-assessed physical activity checklist. 652 Percept Mot Skills. 2004;99(3 Pt 2):1099-102. doi:10.2466/pms.99.3f.1099-1102.

653 70. Affuso O, Stevens J, Catellier D, McMurray RG, Ward DS, Lytle L et al. Validity of self654 reported leisure-time sedentary behavior in adolescents. J Negat Results Biomed. 2011;10:2. 655 doi:10.1186/1477-5751-10-2.

656 71. Taras HL, Sallis JF, Patterson TL, Nader PR, Nelson JA. Television's influence on children's 657 diet and physical activity. J Dev Behav Pediatr. 1989;10(4):176-80.

658 72. Brener ND, Kann L, McManus T, Kinchen SA, Sundberg EC, Ross JG. Reliability of the 6591999 youth risk behavior survey questionnaire. J Adolesc Health. 2002;31(4):336-42. 
660 73. Bonn SE, Bergman P, Trolle Lagerros Y, Sjolander A, Balter K. A validation study of the

661 Web-Based Physical Activity Questionnaire Active-Q against the GENEA accelerometer. JMIR

662 Res Protoc. 2015;4(3):e86. doi:10.2196/resprot.3896.

663 74. Oostdam N, van Mechelen W, van Poppel M. Validation and responsiveness of the AQuAA

664 for measuring physical activity in overweight and obese pregnant women. J Sci Med Sport.

665 2013;16(5):412-6. doi:10.1016/j.jsams.2012.09.001.

666 75. Clark BK, Lynch BM, Winkler EA, Gardiner PA, Healy GN, Dunstan DW, Owen N. Validity

667 of a multi-context sitting questionnaire across demographically diverse population groups:

668 AusDiab3. Int J Behav Nutr Phys Act. 2015;12:148.

669 76. Fjeldsoe BS, Marshall AL, Miller YD. Measurement properties of the Australian Women's

670 Activity Survey. Med Sci Sports Exerc. 2009;41(5):1020-33.

671 doi:10.1249/MSS.0b013e31819461c2.

672 77. Clemes SA, David BM, Yi Z, Xu H, Brown W. Validity of two self-report measures of sitting

673 time. J Phys Act Health. 2012;9(4):533-9.

674 78. Hekler EB, Buman MP, Haskell WL, Conway TL, Cain KL, Sallis JF, Saelens BE, Frank LD,

675 Kerr J, King AC. Reliability and validity of CHAMPS self-reported sedentary-to-vigorous

676 intensity physical activity in older adults. J Phys Act Health. 2012;9(2):225-36.

677 79. Jefferis BJ, Sartini C, Ash S, Lennon LT, Wannamethee SG, Whincup PH. Validity of

678 questionnaire-based assessment of sedentary behaviour and physical activity in a population-

679 based cohort of older men; comparisons with objectively measured physical activity data. Int J

680 Behav Nutr Phys Act. 2016;13:14. doi:10.1186/s12966-016-0338-1.

681 80. Visser M, Koster A. Development of a questionnaire to assess sedentary time in older

682 persons--a comparative study using accelerometry. BMC Geriatr. 2013;13:80. doi:10.1186/1471$683 \quad 2318-13-80$. 
684 81. Gomersall SR, Olds TS, Ridley K. Development and evaluation of an adult use-of-time 685 instrument with an energy expenditure focus. J Sci Med Sport. 2011;14(2):143-8.

686 doi:10.1016/j.jsams.2010.08.006.

687 82. Gomersall SR, Pavey TG, Clark BK, Jasman A, Brown WJ. Validity of a self-report recall 688 tool for estimating sedentary behavior in adults. J Phys Act Health. 2015;12(11):1485-91. 689 doi:10.1123/jpah.2014-0602.

690 83. van Nassau F, Chau JY, Lakerveld J, Bauman AE, van der Ploeg HP. Validity and 691 responsiveness of four measures of occupational sitting and standing. Int J Behav Nutr Phys Act. 692 2015;12:144. doi:10.1186/s12966-015-0306-1.

693 84. Wick K, Faude O, Schwager S, Zahner L, Donath L. Deviation between self-reported and 694 measured occupational physical activity levels in office employees: effects of age and body 695 composition. Int Arch Occup Environ Health. 2016;89(4):575-82. doi:10.1007/s00420-015-10956961.

697 85. Orsini N, Bellocco R, Bottai M, Hagstromer M, Sjostrom M, Pagano M, Wolk A. Validity of 698 self-reported total physical activity questionnaire among older women. Eur J Epidemiol. 699 2008;23(10):661-7. doi:10.1007/s10654-008-9273-z.

700 86. Yi SS, Bartley KF, Firestone MJ, Lee KK, Eisenhower DL. Self-reported sitting time in New 701 York City adults, the Physical Activity and Transit Survey, 2010-2011. Prev Chronic Dis. 702 2015;12:E85. doi:10.5888/pcd12.140488.

703 87. Matthews CE, Keadle SK, Sampson J, Lyden K, Bowles HR, Moore SC, Libertine A, 704 Freedson PS, Fowke JH. Validation of a previous-day recall measure of active and sedentary 705 behaviors. Med Sci Sports Exerc. 2013;45(8):1629-38. doi:10.1249/MSS.0b013e3182897690. 706 88. Shuval K, Kohl HW, Bernstein I, Cheng Dl, Gabriel KP, Barlow CE, Yinghui L, DiPietro L. 707 Sedentary behaviour and physical inactivity assessment in primary care: the Rapid Assessment 
708 Disuse Index (RADI) study. Br J Sports Med. 2014;48(3):250-5. doi:10.1136/bjsports-2013-

709092901.

710 89. Chau JY, van der Ploeg HP, Dunn S, Kurko J, Bauman AE. A tool for measuring workers'

711 sitting time by domain: the Workforce Sitting Questionnaire. Br J Sports Med. 2011;45(15):1216-

712 22. doi:10.1136/bjsports-2011-090214.

713 90. Clark BK, Thorp AA, Winkler EA, Gardiner PA, Healy GN, Owen N, Dunstan DW. Validity

714 of self-reported measures of workplace sitting time and breaks in sitting time. Med Sci Sports

715 Exerc. 2011;43(10):1907-12. doi:10.1249/MSS.0b013e31821820a2. 


\section{Figure 1 (on next page)}

Flow diagram of literature search for adult questionnaires

$\mathrm{SB}=$ sedentary behaviour, $\mathrm{SB}=$ Sedentary Behaviour Research Network 


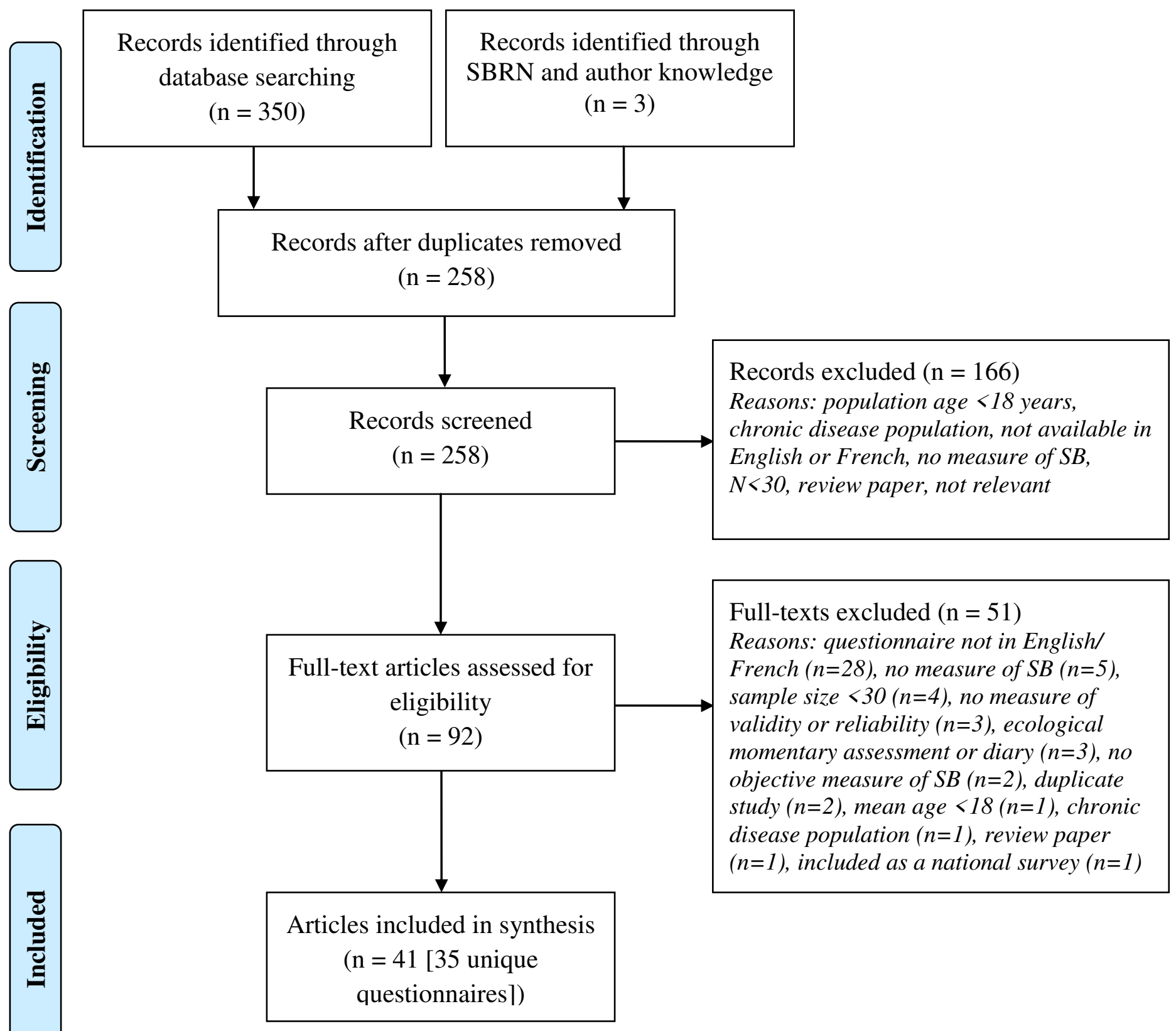


Table $\mathbf{1}$ (on next page)

Suggested sedentary behaviour module 
Table 1 Suggested sedentary behaviour module in English and French

\section{ISAT (International Sedentary Assessment Task)}

Outil international d'évaluation du comportement sédentaire (ISAT - Version française)

The following questions are about activities you/your child did over the past week while sitting or lying down. Do not count the time you/they spent in bed sleeping or napping.

Les questions suivantes portent sur des activités que vous (ou votre enfant) avez réalisées durant la dernière semaine, alors que vous étiez assis ou allongés. Ne pas considérer le temps que vous (ou votre enfant) avez passé au lit à dormir ou faire la sieste.

For each of the following activities (questions 1, 2, 3, and 6) only count the time when this was your/their main activity.

For example if you/they are watching television and surfing the internet, count it as television time or computer time, but not as both. [adapted from MOST questionnaire]

Ne comptez le temps alloué à chacune des activités suivantes (questions 1, 2, 3 et 6) que lorsqu'il s'agissait de votre activité principale (ou de celle de votre enfant). Par exemple, si vous (ou votre enfant) regardez la télévision ET naviguez sur Internet, veuillez compter soit le temps de télévision soit le temps d'ordinateur, mais non les deux.

On a typical WEEKDAY/WEEKEND DAY in the past week, how much time do you/your child spend sitting or lying down and... [adapted from SBQ and MOST questionnaires]

La semaine passée, lors d'une journée habituelle de semaine/fin de semaine, combien de temps avezvous (ou votre enfant) passé assis ou allongé à...

\begin{tabular}{|c|c|c|c|c|}
\hline $\begin{array}{l}\text { SEDENTARY ITEM } \\
\text { ACTIVITÉS SÉDENTAIRES }\end{array}$ & TEMI & OUÉ & $\begin{array}{l}\text { SOURCE } \\
\text { SOURCE }\end{array}$ & $\begin{array}{l}\text { MODIFICATIONS } \\
\text { MODIFICATIONS }\end{array}$ \\
\hline $\begin{array}{l}\text { 1. Watching TV or using a } \\
\text { computer, tablet or } \\
\text { smartphone or [for children } \\
\text { and youth only: during } \\
\text { your/their free time?]* } \\
\text { 1. Regarder la télévision ou }\end{array}$ & $\begin{array}{c}\text { _ hours } \\
\text { _ heures }\end{array}$ & $\begin{array}{l}\text { minutes } \\
\text { minutes }\end{array}$ & $\begin{array}{l}\text { CHMS } \\
\text { ECMS }\end{array}$ & $\begin{array}{l}\text { iPad is no longer } \\
\text { specifically } \\
\text { referenced in } \\
\text { question. } \\
\text { L'utilisation d'un } \\
\text { iPad n'est plus }\end{array}$ \\
\hline
\end{tabular}


utiliser votre ordinateur, tablette ou téléphone intelligent [pour les enfants et adolescents seulement: lors de ton/son temps libre?]*

(Count time watching videos, playing computer games, emailing or using the Internet. Do not include time spent on a computer at work or at school.) (Compter le temps passé à regarder des vidéos, jouer sur l'ordinateur, consulter ses courriels ou naviguer sur Internet. Ne pas inclure le temps passé sur un ordinateur au travail ou à l'école.)

* Note: this question can be omitted if questions $2 \& 3$ are used instead.

*Note: cette question peut ne pas être utilisée si les questions $2 \& 3$ sont utilisées à la place.

2. Watching television or videos [for children and youth only: during your/their free time?]

2. Regarder la télévision ou des vidéos [pour les enfants et adolescents seulement: lors de ton/son temps libre?]*

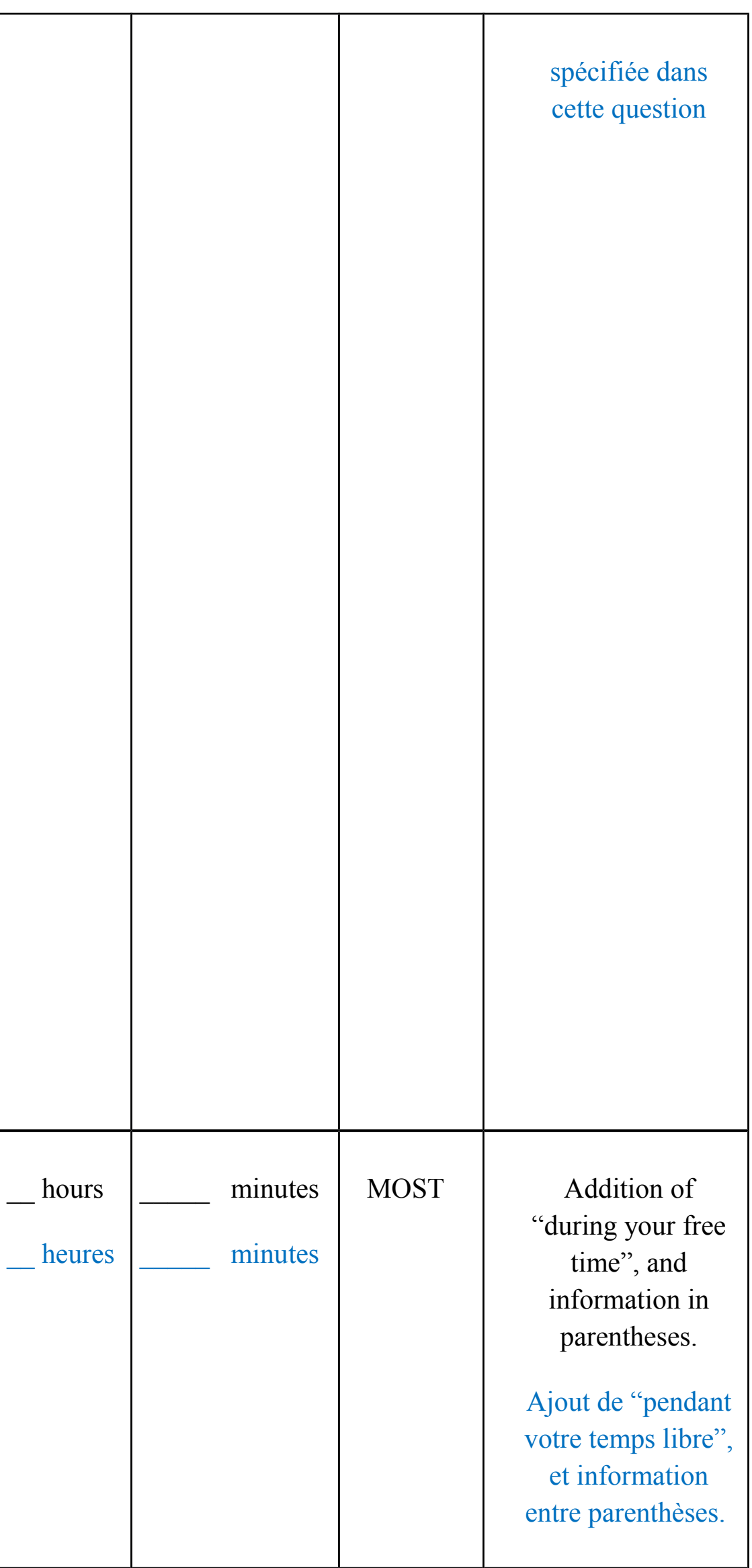




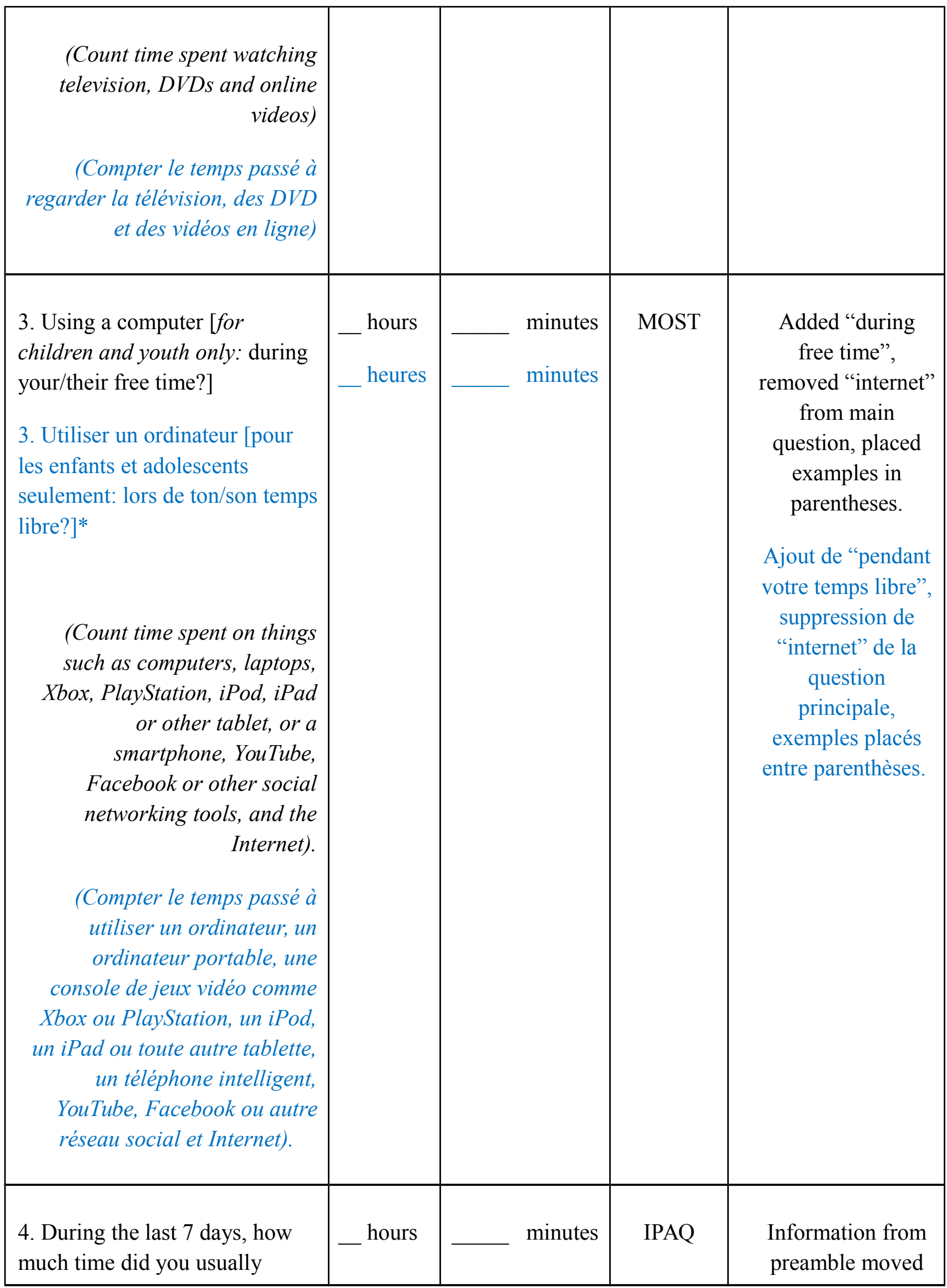


spend sitting on a

week/weekend day?

4. De façon générale, au cours des 7 derniers jours, combien de temps avez-vous passé assis lors des jours de semaine et fin de semaine?

(Include time spent at school or work, at home, while doing course work, and during leisure time. This may include time spent sitting at a desk, visiting friends, reading or sitting or lying down to watch television). (Inclure le temps passé à l'école, au travail, à la maison, à faire les devoirs et pendant les loisirs. Cela peut inclure le temps passé assis à un bureau, avec des amis ou assis ou allongé à lire ou regarder la télévision.)

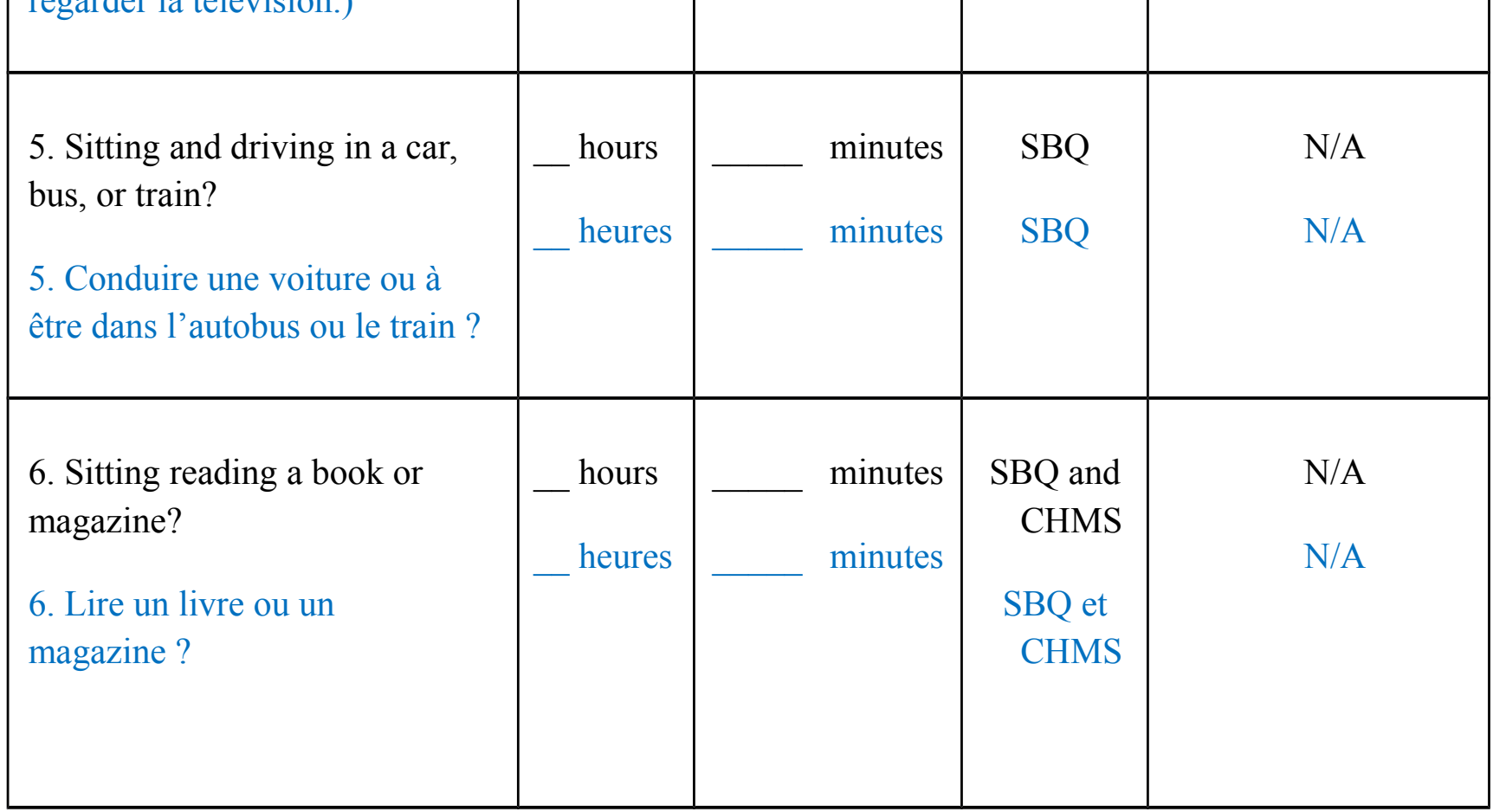


(Only include reading during your free time. Include reading done using electronic formats. Include time spent reading as part of your homework, but do not include time spent reading at work, during class time or while exercising).

(Seulment inclure la lecture pendant votre temps libre. Inclure la lecture sur un appareil électronique et le temps passé à lire pour les devoirs d'école. Ne pas inclure, le temps passé à lire au travail, à l'école ou alors que vous faisiez de l'activité physique.)

Information in square brackets is provided for the reader, but should not be included on the final questionnaire.

Les renseignements entre crochets ne doivent pas être inclus dans la version finale du questionnaire. Information in square brackets is provided for the reader, but should not be included on the final questionnaire. 